NBER WORKING PAPER SERIES

\title{
LEARNING ON THE QUICK AND CHEAP: \\ GAINS FROM TRADE THROUGH IMPORTED EXPERTISE
}

\author{
James R. Markusen \\ Thomas F.Rutherford \\ Working Paper 10603 \\ http://www.nber.org/papers/w10603
NATIONAL BUREAU OF ECONOMIC RESEARCH 1050 Massachusetts Avenue
Cambridge, MA 02138 \\ June 2004
}

The views expressed herein are those of the author(s) and not necessarily those of the National Bureau of Economic Research.

(C2004 by James R. Markusen and Thomas F. Rutherford. All rights reserved. Short sections of text, not to exceed two paragraphs, may be quoted without explicit permission provided that full credit, including (C) notice, is given to the source. 
Learning on the Quick and Cheap: Gains from Trade Through Imported Expertise James R. Markusen and Thomas F. Rutherford NBER Working Paper No. 10603

June 2004

JEL No. F2, F23, O1, O3

\section{$\underline{\text { ABSTRACT }}$}

Gains from productivity and knowledge transmission arising from the presence of foreign firms has received a good deal of empirical attention, but micro-foundations for this mechanism are weak . Here we focus on production by foreign experts who may train domestic unskilled workers who work with them. Gains from training can in turn be decomposed into two types: (a) obtaining knowledge and skills at a lower cost than if they are self-taught at home, (b) producing domestic skilled workers earlier in time than if they the domestic economy had to rediscover the relevant knowledge through "reinventing the wheel". We develop a three-period model in which the economy initially has no skilled workers. Workers can withdraw from the labor force for two periods of self study and then produce as skilled workers in the third period. Alternatively, foreign experts can be hired in period 1 and domestic unskilled labor working with the experts become skilled in the second period. We analyze how production, training, and welfare depend on two important parameters: the cost of foreign experts and the learning (or "absorptive") capacity of the domestic economy.

James R. Markusen

Department of Economics

University of Colorado

Boulder, CO 80309-0256

and NBER

james.markusen@colorado.edu

Thomas F. Rutherford

Department of Economics

University of Colorado

Boulder, CO 80309-0256

rutherford@colorado.edu 


\section{1. $\quad$ Introduction}

Trade regimes across countries are often more liberal than investment regimes which are in turn generally more liberal than restrictions on temporary migration. This is interesting in the context of the literature on the transmission of technical/managerial knowledge and productivity “spillovers” between countries and whether trade or investment is a more important channel of transmission (Keller, 1998, 2002a,b, Gong and Keller 2003).

In the latter vein of literature, several different ideas for the micro-foundations of the transmission mechanism have been proposed or modeled. Theoretical models have looked at linkages as a source of productivity spillover, so that upstream and/or downstream firms benefit from the arrival of multinationals (Markusen and Venables, 1999). This has generally been in the form of variety effects from supporting an increased number of intermediate or final goods. A second stream of theoretical analysis looks at workers or local firms learning from watching or working for foreign firms with a resulting increase in their productivity (Fosfuri, Motta, and Rønde 2001, Glass and Saggi 2002, Ethier and Markusen 1996, Markusen 2001). Empirical work in search of spillovers to local firms include Blomström and Kokko (1998), Blomström and Sjöholm (1999), Aiken and Harrison and Lipsey (1996), Smarzynska (2004), and Smarzynska and Spatareanu (2003). Other empirical literature has documented that local firms and their managers often get their start as employees of multinational firms (Katz 1987, Hobday 1995, Hall and Khan 2003).

Very little in this literature is directed at modeling the precise micro-mechanism of how foreign skilled workers impart those skills to domestic workers. That then is the purpose of this paper. We focus on direct imports of the services of foreign experts as a method of both 
providing an important good or service and for training domestic workers faster and/or cheaper than they can learn on their own. We depart from the tradition of comparative steady-state analysis used in new growth theory, since we want to explicitly consider timing issues rather than merely steady-state levels and growth rates. For this reason, we use a very simple competitive constant-returns model with no spillovers, externalities, or other bells-and-whistles.

The economy lasts three periods and initially has no skilled workers who are needed to produce a non-traded good X. Unskilled workers can withdraw from production (of good Y) for two periods and learn to be skilled workers through a self-learning process ("reinventing the wheel) and become skilled workers in period three.

Instead of relying on learning by studying (LBS), the economy may import foreign experts who have accumulated expertise from previous activities. Foreign experts can produce good X working alone in any period. Alternatively, foreign experts can produce $\mathrm{X}$ in the first/second period and domestic unskilled labor working with them become skilled in the second/third period. We refer to this as learning by watching (LBW). In the latter event, in the second period these newly skilled domestic workers can produce $\mathrm{X}$ and can train additional domestic workers for period 3. As in the case of foreign experts, domestic skilled workers may also produce alone without training additional workers.

We solve for a perfect-foresight, competitive equilibrium, initially with the economy allowed to borrow subject to three-period trade balance constraint. A period-by-period tradebalance constraint is considered in an appendix. There are nine possible training/production activities, and the set of activities operating in equilibrium is referred to as the regime.

An important parameter in the model is the cost of foreign experts in terms of the 
composite other good Y produced by the economy. When this cost is very high, domestic workers engage in LBS and no skilled workers and no X are available until period 3. At a somewhat lower cost, foreign experts are used in period one only and then more domestic skilled workers are trained in period 2 by the domestic workers trained by foreign experts in period 1 . At a yet lower cost, all training is by foreign experts. Finally, at a very low cost, it doesn't pay to train any one, and all production in all periods is done by the foreigners working alone.

Gains from trade are a combination of: more $X$, getting $X$ earlier, cheaper training of domestic workers, and getting domestic skilled workers earlier. $\mathrm{X}$ is available in period 1 , and domestic skilled workers are available in period 2 instead of both of these things occurring first in period 3 when experts are very costly.

A second important parameter is the learning or "absorptive" capacity of the unskilled workers. When this capacity is very low (and experts are moderately priced), experts do all the $\mathrm{X}$ production and no domestic workers engage in LBS or LBW. As this capacity grows, foreign experts are used for fewer periods and switch from production only to production plus training. At high levels of learning capacity, the economy also engages in LBS and no foreign experts are used past the first period.

The model and these results may be interesting in several empirical and policy contexts. From an empirical point of view, it may help interpret a number of findings including the fact that managers of local firms in developing countries often get their start working for multinationals. From a policy point of view, it suggests that foreigners are not substitutes for local skilled labor unless the former are very cheap and/or the latter rather stupid, and that barriers to foreign firms and workers (e.g., visa, residence restrictions) may be costly. 
2. The three-period model

(a) There are three time periods, $\mathrm{t}=1,2,3$

(b) There are two goods, $\mathrm{X}$ and $\mathrm{Y}$; both sectors competitive, constant returns to scale

(c) There are four factors of production, R, L, F, and S

(d) $\quad \mathrm{Y}$ is produced from a sector-specific factor R, and unskilled labor L.

(e) $\mathrm{X}$ is produced from imported experts $\mathrm{F}$ and/or skilled labor $\mathrm{S}$ and is non-traded.

(f) The stock of $\mathrm{R}$ and the initial stock of $\mathrm{L}$ are fixed. Initially there are no S.

Let subscript t denote time period. $Y_{t}$ is produced from $R_{t}$, and $L_{t}$ :

(1) $\quad Y_{t}=Y\left(R_{t}, L_{y t}\right)$

The role of $\mathrm{R}$ is to add convexity to the model: unskilled workers going to train must be drawn from the $\mathrm{Y}$ sector at increasing cost in terms of $\mathrm{Y}$.

Let $L_{t}$ denote the stock of unskilled workers at t, and let $L_{s t}$ give the unskilled workers entering training at $t$. There is one equation for the intra-period allocation of the unskilled worker stock and a second equation for the inter-period change in that stock.

(2) $\quad L_{t}=L_{y t}+L_{s t}$

(3) $L_{t+1}=L_{t}-L_{s t}$

Let $S_{t}$ denote the stock of skilled workers at t, and let $N S_{t}$ denote the newly skilled at $\mathrm{t}$. Skilled workers are produced from unskilled workers L. There are two ways skilled workers can be produced. First, an unskilled worker can go off and study for two period on his/her own and become skilled. Thus unskilled workers who withdraw from the labor force at $\mathrm{t}=1$, are skilled at $\mathrm{t}=3$. 


$$
N S_{3}=L_{s 1} \quad \text { Self-learning activity }
$$

The second is to work with existing skilled workers. An unskilled worker who works alongside a skilled worker in producing $X$ becomes skilled in one time period rather than two. LBW is more efficient than LBS.

When permitted, foreign skilled workers, called foreign experts (or just experts), can also be hired from abroad and paid for at a fixed rental price in terms of Y. When the economy is open, foreign experts can be hired at $\mathrm{t}=1,2,3$. They can produce $\mathrm{X}$ working alone (as can domestic skilled workers) or a domestic unskilled worker can work along side the expert (or domestic skilled worker) and become skilled in one period. Thus trade offers both X consumption earlier at $\mathrm{t}=1$ and allows domestic skilled workers to be produced more cheaply and earlier at $\mathrm{t}=2$. Both are only available at $\mathrm{t}=3$ in autarky.

$$
X_{t}=F_{t} \quad X_{t}=S_{t} \quad \text { Production only activities }
$$

$$
\begin{array}{ll}
\min \left[X_{t}, N S_{t+1}\right]=\max \left[F_{t}, L_{s t}\right] & \text { Production/training activities (foreigners) } \\
\min \left[X_{t}, N S_{t+1}\right]=\max \left[S_{t}, L_{s t}\right] & \text { Production/training activities (domestic) }
\end{array}
$$

We assume no skills depreciation and so the equation of motion for $\mathrm{S}$ is

$$
S_{t+1}=S_{t}+N S_{t+1}
$$

There are nine activities relating to $\mathrm{X}$ and/or training over the three period (several activities may be active at the same time). Codes to denote $\mathrm{X}$ production and/or training activity are give by a three-digit index: IJT.

$$
\mathrm{I}=\mathrm{D}, \mathrm{F} \quad \mathrm{D} \text { denotes a domestic activity using no foreign experts }
$$

$\mathrm{F}$ is an activity involving foreign experts 


$$
\begin{array}{ll}
\mathrm{J}=\mathrm{S}, \mathrm{N} & \mathrm{S} \text { denotes an activity involving training skilled workers } \\
& \mathrm{N} \text { denotes an activity without no training } \\
\mathrm{T}=1,2,3 \quad \text { Time period }
\end{array}
$$

All activities involve production of X except DT1, where domestic workers begin self-study for two period, and produce no $\mathrm{X}$ until $\mathrm{T}=3$.

At $\mathrm{t}=1$ :

(A) domestic unskilled workers study alone, no production DS1

(B) foreign experts working with unskilled domestics who become skilled at $\mathrm{t}=2$. FS1

(C) foreign experts working alone $\quad$ FN1

At $\mathrm{t}=2$ :

(D) domestic skilled workers working with unskilled domestics who become skilled at $\mathrm{t}=3$. DS2

(C) domestic skilled workers working alone ${ }^{1} \quad$ DN2

(B) foreign experts working with unskilled domestics who become skilled at $\mathrm{t}=3 . \quad$ FS2

(D) foreign experts working alone $\quad$ FN2

At $\mathrm{t}=3$.

(A) domestic skilled workers working alone DN3

(B) foreign experts working alone FN3

There is no discounting. When hiring foreigners is permitted, Y produced in any period can be exchanged for consultants in any period at a fixed price. This gives an intertemporal budget constrained allowing borrowing in early periods. Alternatively, the economy must pay for the consultants with Y produced in the period in which the consultants are used.

Notation is as follows:

${ }^{1}$ Note that DS2 and DN2 can only be positive if FS1 is positive. 
$\mathrm{Y}_{\mathrm{i}}, \mathrm{p}_{\mathrm{yi}} \quad$ quantity and price of good $\mathrm{Y}$ at time $\mathrm{t}=\mathrm{i}$

$\mathrm{R}_{\mathrm{i}}, \mathrm{P}_{\mathrm{ri}} \quad$ quantity and price of $\mathrm{Y}$-sector-specific factor $\mathrm{R}$ at time $\mathrm{t}=\mathrm{i}$

$\mathrm{L}_{\mathrm{i}}, \mathrm{P}_{\mathrm{li}} \quad$ quantity and asset price (not rental price) of unskilled labor $\mathrm{L}$ at time $\mathrm{t}=\mathrm{i}^{2}$

$\mathrm{U}_{\mathrm{i}}, \mathrm{p}_{\mathrm{ui}} \quad$ quantity and (rental) price of unskilled labor $\mathrm{U}$ at time $\mathrm{t}=\mathrm{i}$

$\mathrm{S}_{\mathrm{i}}, \mathrm{p}_{\mathrm{si}} \quad$ quantity and (rental) price of skilled labor $\mathrm{S}$ at time $\mathrm{t}=\mathrm{i}$

$\mathrm{F}_{\mathrm{i}}, \mathrm{p}_{\mathrm{fi}} \quad$ quantity and price of foreign experts $\mathrm{F}$ at time $\mathrm{t}=\mathrm{i}$

$E_{i}, P_{e i} \quad$ quantity and price of "foreign exchange" at time $t=i$

$\mathrm{X}_{\mathrm{i}}, \mathrm{p}_{\mathrm{xi}} \quad$ quantity and price of good $\mathrm{X}$ at time $\mathrm{t}=\mathrm{i}$

Factors $\mathrm{R}_{\mathrm{i}}$ and $\mathrm{L}_{1}$ are fixed quantities. $\mathrm{L}_{2}$ and $\mathrm{L}_{3}$ are variables, since labor available for unskilled work is reduced by the number of workers entering training. E is an artificial good: Y can be exchanged (exported) for E and E can then be exchanged for imported foreign experts F. With borrowing and lending allowed, E carries no subscript and thus exports of $\mathrm{Y}$ in any period can be exchanged for foreign experts in any period (zero interest rate). With no borrowing or lending, $Y_{i}$ is exchanged for $E_{i}$ which is exchanged for $F_{i}$.

A key parameter in the model is cost, which is the number of units of $\mathrm{Y}$ that must be exchanged for one for expert. A second parameter is ac ("absorptive capacity”), which give the efficiency units of skilled labor resulting from the training of one unskilled worker. Higher levels of cost are bad, higher levels of ac are good. The parameter cost will impact primarily on the substitution between LBS and LBW, while the parameter ac will impact primarily on the substitution between using experts solely for production and using them (and the LBS activity)

\footnotetext{
${ }^{2}$ Analogous to the price of a unit of capital, $\mathrm{p}_{\mathrm{li}}$ is the present value at $\mathrm{t}=\mathrm{i}$ of a unit of unskilled labor. $\mathrm{p}_{\text {ui }}$, following line, is the single period rental price of unskilled labor at $\mathrm{t}=\mathrm{i}$.
} 
for training as well. ${ }^{3}$

Convexity in the model comes from the fixed factor $\mathrm{R}$ in the $\mathrm{Y}$ sector, which is assumed Cobb-Douglas in the simulations: labor is drawn into training and $\mathrm{X}$ production at increasing cost in terms of $\mathrm{Y}$, with $\mathrm{c}_{\mathrm{yi}}\left(\mathrm{P}_{\mathrm{ui}}\right.$, $\left.\mathrm{P}_{\mathrm{ri}}\right)$ denoting the unit cost function for $\mathrm{Y}_{\mathrm{i}}$. In the $\mathrm{X}$ sector, units are chosen such that one domestic or foreign skilled worker produces one unit of $\mathrm{X}$ and, when training is involved, one unskilled worker works with one skilled worker (fixed coefficients) and that unskilled worker becomes one skilled worker for all future time periods (no skills depreciation).

Utility or welfare is treated as a produced good. The flow of utility in period i and the price of obtaining a unit of utility is

$\mathrm{W}_{\mathrm{i}}, \mathrm{p}_{\mathrm{wi}} \quad$ quantity and price of welfare at $\mathrm{t}=\mathrm{i}$

$\mathrm{W}, \mathrm{p}_{\mathrm{w}} \quad$ quantity and price of intertemporal utility

The price of utility in period i and overall are given by standard cost or unit expenditure functions, denoted $\mathrm{c}_{\mathrm{wi}}\left(\mathrm{p}_{\mathrm{y} i}, \mathrm{p}_{\mathrm{xi}}\right)$ and $\mathrm{c}_{\mathrm{w}}\left(\mathrm{p}_{\mathrm{w} 1}, \mathrm{p}_{\mathrm{w} 2}, \mathrm{p}_{\mathrm{w} 3}\right)$ respectively. A CES with an elasticity of substitution greater than one is assumed in these functions to ensure a solution with $\mathrm{X}_{1}=\mathrm{X}_{2}=0$ in autarky (a value of 3 is used in the simulations within and between periods).

One final assumption before presenting the equations of the model. The model has an implicit contracting assumption in training/production activities, but it is incorrect to say that foreign experts capture rents. In competitive equilibrium, foreign experts earn their opportunity cost which is the constant, exogenous value of working at home. Workers going into self

${ }^{3}$ cost and $a c$ are exogenous to the economy. $a c$ is reflecting an inherent ability to learn. Some of the empirical articles referenced above essentially suggested that absorptive capacity is endogenous and depends on existing skills and education. Endogenizing $a c$ is beyond the scope of this paper, but we can certainly think of it as being inherited from past choices in, for example, educational infrastructure. 
learning or training earn their opportunity cost which is being an unskilled worker for three periods. "Rents” (gains from trade) from lower foreign experts' cost accrue to the domestic representative consumer (all workers receive the three-period unskilled real wage, but that rises with access to the foreign experts).

As defined earlier, $p_{l 1}$ denote the "asset" price of an unskilled worker in the first period; that is, the three-period unskilled wage. Suppose that FS1 is active in equilibrium, earning zero profits while FN1 (production only) is inactive in equilibrium, implying negative profits if it were operated. The dual of (6) gives us that the costs of FS1 (unskilled worker price plus expert's wage) equals revenue (second and third period unskilled wages plus the price of X), while the dual of (5) is unprofitable:

$$
p_{l 1}+p_{f 1}=p_{s 2}+p_{s 3}+p_{x 1} \quad p_{f 1}>p_{x 1}
$$

Together, these imply that

$$
\begin{array}{ll}
p_{s 2}+p_{s 3}-p_{l 1}>0 & \text { positive rents from training, equals } \\
p_{f 1}-p_{x 1}>0 & \text { excess of foreign expert's wage over value of } \mathrm{X} \text { output }
\end{array}
$$

This can only be supported as an equilibrium if the competitive firms and workers can write binding contracts at $\mathrm{t}=1$ which pays the worker the three-period unskilled wage, or by some other institutional arrangement such as bonding. To interpret it slightly differently, the unskilled worker could make a payment for training that leaves him with his opportunity costs, and this payment (when positive) allows an otherwise unprofitable production activity (X production only, no training) to operate. ${ }^{4}$

\footnotetext{
${ }^{4}$ Economic historian Ann Carlos tells us that the consensus in the apprenticeship literature is that the apprentices were a losing proposition in early years but that the apprenticeship period ran about two
} 
The general-equilibrium model is a non-linear complementarity problem in mathematical programming language: a set of inequalities each with an associated non-negative variable. If an inequality holds as an equation the complementary variable is generally positive, and the complementary variable is zero if the associated inequality holds as a strict inequality in equilibrium.

There are three classes of inequalities in the model. First, there is a zero-profit inequality for each activity: unit cost must be greater than or equal to the price of the complementary good or factor. The complementary variables are activity levels, include production/training activities, labor supply activities, and trading activities. Second, there is a set of market clearing conditions for each good/factor, with prices as complementary variables. Third, there is an income balance or trade balance condition for the economy. For completeness, we present the entire list of inequalities and complementary variables in the next section. This can probably be skipped by readers interested in going to the simulation results in sections 4 and 5 .

years after the master broke even, during which time he recouped his loss. Often families paid masters to take their sons, and legal institutions were developed to enforce the contract and return runaways to their masters. 
3. The full model: inequalities and unknowns (may be skipped)

Zero-profit Inequality

$c_{y i}\left(p_{u i}, p_{r i}\right) \geq p_{y i}$

$p_{l i} \geq p_{l i+1}+p_{u i}$

$p_{l 1} \geq p_{s 3} * a c$

$p_{l 1}+p_{f 1} \geq p_{s 2} * a c+p_{s 3} * a c+p_{x I}$

$p_{f 1} \geq p_{x 1}$

$p_{l 2}+p_{f 2} \geq p_{s 3} * a c+p_{x 2}$

$p_{f 2} \geq p_{x 2}$

$p_{l 2}+p_{s 2} \geq p_{s 3} * a c+p_{x 2}$

$p_{s 2} \geq p_{x 2}$

$p_{f 3} \geq p_{x 3}$

$p_{s 3} \geq p_{x 3}$

$p_{e} * \cos t \geq p_{f i}$

$p_{y i} \geq p_{e}$

$c_{w i}\left(p_{y i}, p_{x i}\right) \geq p_{w i}$

$c_{w}\left(p_{w 1}, p_{w 2}, p_{w 3}\right) \geq p_{w}$ $\underline{\text { Complementary variable }}$

$Y_{i}$

$U_{i}$

$D S 1$

FS1

FN1

$F S 2$

FN2

$D S 2$

DN2

FN3

DN3

$F_{i}$

$E Y_{i}$

$W_{i}$

W
Production activity $Y_{i}$

Unskilled labor supply to $Y_{i}{ }^{5}$

$S_{3}$ produced from activity $D S 1$

$X_{1}=S_{2}=S_{3}$ from activity FS1

$X_{1}$ from activity $F N 1$

$X_{2}=S_{3}$ from activity FS2

$X_{2}$ from activity FN2

$X_{2}=S_{3}$ from activity $D S 2$

$X_{2}$ from activity $D N 2$

$X_{3}$ from activity FN3

$X_{3}$ from activity $D N 3$

Imports of experts at $\mathrm{t}=\mathrm{i}$

Exports of $\mathrm{Y}$ at $\mathrm{t}=\mathrm{i}$

Sub-welfare at $\mathrm{t}=\mathrm{i}$

Total (present value) of welfare

The next set of inequalities are market clearing conditions for each of the goods, factors, and trade activities. The complementary variables are prices of these quantity variables. Inequalities are written as supply greater than or equal to demand, where a strictly greater-than relationship

${ }^{5}$ Activities $U_{\mathrm{i}}$ account for change in the unskilled labor stock as workers move into training and production. Activity $\mathrm{U}_{1}$ has $\mathrm{L}_{1}$ as the input and $\mathrm{U}_{1}$ (used in $\mathrm{Y}_{1}$ ) and $\mathrm{L}_{2}$ as outputs. Activity $\mathrm{U}_{2}$ has $\mathrm{L}_{2}$ as the input and $\mathrm{U}_{2}$ (used in $\mathrm{Y}_{2}$ ) and $\mathrm{L}_{3}$ as outputs. 
implies that the price is zero (a free good) in equilibrium. Demands for goods/factors exploit Shephard's lemma in activities $\mathrm{Y}_{\mathrm{i}}$ and $\mathrm{W}_{\mathrm{i}}$ where there is variable substitution among inputs.

\section{Market-clearing inequality Complementary variable Description}

$$
\begin{array}{lll}
Y_{i}>\frac{\partial c_{u i}}{\partial p_{y i}} W_{i} & p_{y i} & \text { Supply - demand for } \mathrm{Y}_{\mathrm{i}} \\
U_{i}>\frac{\partial c_{y i}}{\partial p_{u i}} Y_{i} & p_{u i} & \text { Supply - demand for } \mathrm{U}_{\mathrm{i}} \\
R_{i}>\frac{\partial c_{y i}}{\partial p_{r i}} Y_{i} & p_{r i} & \\
L_{1} \geq U_{1}+F S 1+D S 1 & & \text { Supply - demand for } \mathrm{R}_{\mathrm{i}} \\
U_{1} \geq U_{2}+F S 2+D S 2 & p_{l 1} & \\
U_{3} \geq U_{2} & p_{l 2} & \text { Supply - demand for } \mathrm{L}_{1} \\
F S 1 \geq D S 2+D N 2 & p_{l 3} & \text { Supply - demand for } \mathrm{L}_{2} \\
D S 1+F S 1+D S 2+F S 2 & p_{s 2} & \text { Supply - demand for } \mathrm{L}_{3} \\
F_{1} \geq F S 1+F N 1 & p_{s 3} & \text { Supply - demand for } \mathrm{S}_{2} \\
F_{2} \geq F S 2+F N 2 & p_{f 1} & \text { Supply - demand for } \mathrm{S}_{3} \\
F_{3} \geq F N 3 & p_{f 2} & \text { Supply - demand for } \mathrm{F}_{1} \\
F S 1+F N 1 \geq \frac{\partial c_{w 1}}{\partial p_{x 1}} W_{1} & p_{f 3} & \text { Supply - demand for } \mathrm{F}_{2} \\
& p_{x 1} & \text { Supply - demand for } \mathrm{F}_{3} \\
& & \text { Supply - demand fo } \mathrm{X}_{1} \\
& &
\end{array}
$$$$
F S 2+F N 2+D S 2+D N 2 \geq \frac{\partial c_{w 2}}{\partial p_{x 2}} W_{2} \quad p_{x 2}
$$$$
\text { Supply - demand for } \mathrm{X}_{2}
$$$$
F N 3+D N 3 \geq \frac{\partial c_{w 3}}{\partial p_{w 3}} W_{3}
$$$$
p_{x 3}
$$$$
\text { Supply - demand for } \mathrm{X}_{3}
$$ 


$\begin{array}{lll}W_{i} \geq \frac{\partial c_{w i}}{\partial p_{w i}} W & p_{w i} & \text { Supply - demand for } \mathrm{W}_{\mathrm{i}} \\ W \geq I / p_{w} & p_{w} & \text { Supply - demand for } \mathrm{W} \\ \sum E Y_{i} \geq \sum \operatorname{cost}_{i} F_{i} & p_{e} & \text { Supply - demand for foreign exch }\end{array}$

Income balance equation $\quad$ Complementary Variable $\quad$ Description
$I=p_{l 1} L_{1}+\sum p_{r i} R_{i}$
I Income balance

In all, the model then consists of 51 inequalities in 51 unknowns. One equation is redundant by Walras’ Law, so the price of “foreign exchange”, $\mathrm{p}_{\mathrm{e}}$ is used as numeraire and the corresponding equation is dropped from the model. The model is coded in Rutherford's MPS/GE, a subsystem of GAMS and solve using the non-linear complementarity solver in GAMS. 


\section{4. $\quad$ Results 1: varying the cost of foreign experts}

Figures 1-4 consider different levels of cost, solving the general-equilibrium model for each level. Figure 1 gives qualitative information on the equilibrium regime for differing levels of cost. That is, each row of the Figure gives a the general-equilibrium solution to the model for the range of cost shown in the first column.

The first row of Figure 1 is autarky, cost so high that the economy uses no foreigners. In this case, the self-training activity is the only one that operates and no skilled workers and no X are available until $t=3$. At a somewhat lower, but still high, level of cost, activity FS1 becomes active, so foreign experts are used sparingly for only period only in the production/training activity (so this corresponds to (9)-(11) above). The newly-skilled domestic workers at $\mathrm{t}=2$ train more domestic workers at $\mathrm{t}=2$ : DS2 is active.

As we go to progressively lower levels of cost, self-training is not used, and then additional domestic training in period 2 stops. Foreign workers begin to be used for production only, and when they get very cheap, there is no training at all and foreigners do all the production: the regime is FN1, FN2, FN3.

In order to show quantitative results, we rotate Figure 1, showing the cost of foreign experts, the exogenous variable, on the horizontal axis of Figure 2-4. Each column of Figures 24 represents an independent general-equilibrium solution to the model. Moving to the right represents solution to successive runs of the model, not moving through time. On the left of the horizontal axis, cost is prohibitively high, while on the right-hand edge foreign experts are cheap. Thus moving left to right corresponds to moving from economies facing a very high cost of experts toward economies facing a low-cost situation (cost is a trade cost variable, not a tariff, so 
there is no income effect of tariff revenue, and its value is exogenous to the government).

Figure 2 shows the number of domestic workers who are skilled by period 3, dividing them into self trained, trained by foreign experts in period 1 (FS1) and those trained by foreigntrained domestic workers in period 2 (DS2). As the cost of foreign experts falls, we see that self training falls to zero. Over regimes 2 and 3 (vertical dotted lines separate regimes), FS1 = DS2 since every domestic worker foreign trained at $t=1$ trains another domestic worker at $t=2$. But in regime 4, not all workers foreign-trained at $\mathrm{t}=1$ train an addition worker and instead an increasing number produce without training (DN2). In regime 5, training of additional workers at $t=2$ ceases entirely. In regime 6 , training by experts declines toward zero.

This last regime shift, in which all training ceases, can be thought of in terms of equation (9) above. Skilled wages are driven down relative to the unskilled wage in periods 2 and 3 sufficiently that the zero-profit condition for FS1 becomes slack and that for FN1 holds with equality.

$$
p_{l 1}+p_{f 1}>p_{s 2}+p_{s 3}+p_{x 1} \quad p_{f 1}=p_{x 1}=>\quad \sum p_{u i}=p_{l 1}>p_{s 2}+p_{s 3}
$$

Up to regime 6, the number of skilled workers trained and the number working are the same, since skilled workers at $\mathrm{t}=3$ are all domestic trained in activities DS1, FS1 and/or DS2. But again, once foreign experts are sufficiently cheap, training declines toward zero as foreigners are used for production only, training becoming unprofitable. Taken together, these results imply that, over a substantial range, the use of foreign experts and the training of domestic skilled workers are complements, but that they become substitutes as foreign experts become very cheap.

Figure 3 graphs the total number of domestic workers who are trained by $t=3$, and the 
cumulative number of domestic skilled-worker years. This illustrates that the advantages offered by increasingly cheaper foreigners are taken in the form of getting skilled workers earlier, rather than having more skilled workers at $\mathrm{t}=3$, until the foreign experts are truly cheap.

In spite of the complicated regime shifting as foreign experts become cheaper, our intuition would suggest that two things ought to rise monotonically with lower cost of experts. First, cumulative X production ought to rise continuously and so should intertemporal welfare. Both suspicions are correct. Cumulative X production which does indeed rise monotonically. Figure 4 shows welfare and $\mathrm{X}$ production/consumption in each time period as a function of the cost of experts. Welfare rises steadily as cost falls as intuition would suggest. However, it is interesting to note that the gains from trade are taken over a large range of costs in the form of earlier consumption of $\mathrm{X}$; indeed, there is a range over which $\mathrm{X}_{3}$ declines. Perfect smoothing is achieved after the shift to regime 5 , where additional training of workers at $t=2$ ceases (DS2 becomes inactive). At this point and over all of regime 5 , there is an equal number of skilled workers in all time periods ( $\mathrm{n}$ experts at $\mathrm{t}=1$ produce $\mathrm{n}$ domestic skilled workers for periods 2 and 3 using FT1), and so an equal X output in all time periods.

The appendix to the paper illustrates the effects of imposing a period-by-period tradebalance constraint. 


\section{5. $\quad$ Results 2: varying learning capacity}

Now consider a different experiment. Suppose that foreign experts are available at a constant moderate cost, but we vary the parameter ac (absorptive capacity) which gives the number of efficiency units of skilled labor produced when an unskilled laborer is trained. We assume that this applied to both the self-training activity and production/training activities. Production functions are given as follows.

$$
\begin{aligned}
& N S_{t 3} / a c=L_{s 1} \\
& \min \left[X_{t}, N S_{t+1} / a c\right]=\max \left[E_{t}, L_{s t}\right] \\
& \min \left[X_{t}, N S_{t+1} / a c\right]=\max \left[S_{t}, L_{s t}\right]
\end{aligned}
$$

We begin with this value very low, so that initially all production is done by foreign experts and no training is done whether by LBS or LBW. An economy with low capacity is stagnant, consuming the same amount every period. ${ }^{6}$

Regimes are shown in Figure 5, using the same format as Figure 1. Each row is a solution to the general-equilibrium model, with capacity or capability rising as we move down the vertical axis. Initially, all production is done by foreign experts and there is no training as just noted. For economies with a higher capacity, we see that activity FS1 becomes active, and some domestic workers are trained for periods 2 and 3, but non-training production activities by foreigners FN2 and FN3 continue to be used in regimes 2 and 3. In regime 4, production-only activities FN2 and DN2 cease and DS2 becomes active: some workers trained by foreigners in period 1 train additional domestic workers in period 2. In regime 5, FN3 becomes inactive, so

${ }^{6}$ This simulation uses a value of cost $=8$. ac was set at 1 in Figure 1-4; here we concentrate on lower values to illustrate the region of interesting action. 
from this point on foreign experts are only used in activities with training. In regime 6, DS1 becomes active, as it now pays some workers to begin LBS in period $1 .^{7}$ Finally, use of foreign experts after $\mathrm{t}=1$ ceases in regime 7 . Foreign experts are only used to train some workers at $\mathrm{t}=$ 1 , who then train additional workers at $t=2$, the latter joining LBS workers as skilled workers in period 3.

Figure 6 presents the same information as Figure 2. Again, each column is a general equilibrium solution, with movements to the right being movements to higher-capacity economies, not a movement through time. In the present case, there is no training/learning initially. All production is by foreign experts working alone. Then we have a region in which all training is done by foreign experts. Then some of those trained undertake additional training in period 2 (DS2). The "experts” and “domestic” curves come together when additional training by experts at $\mathrm{t}=2$ ceases $(\mathrm{FS} 2=0$ ) and each domestic worker train by a foreign expert at $\mathrm{t}=1$ trains an additional worker at $\mathrm{t}=2$ (FS1 $=$ DS2). Then the self-training activity becomes active (DS1 > 0). Thus as capacity improves, an increasingly large share of domestic skilled workers are self or domestic trained.

Figure 7 shows the use of foreign experts by period. While the total number of foreign experts continues to rise for economies of successively higher capacities, it is clear that the use of foreigners moves earlier in time. Their role is to help “jump start” the process, allowing $\mathrm{X}$ to be consumed in period 1 and domestic skilled workers to be produced for period 2 .

Figure 8 presents this information another way, showing the number of foreigners used in production-only activities versus training activities. The number of domestic workers in self-

\footnotetext{
${ }^{7}$ With reference to the previous footnote, DS1 (LBS) would never be active at lower values of cost, one reason we chose a moderately high value in this simulation.
} 
study and being trained by other skilled domestic workers is also shown. Economies with low capacity rely on foreigners to produce $\mathrm{X}$ in all periods, but production-only activities are replaced by those with training at higher capacities. Eventually, the use of foreigners for training is overtaken by self-study and training by skilled domestic workers.

Taken together, Figures 6-8 show that economies with successively higher capacities (a) rely proportionately less on foreigner experts, (b) use foreign experts for a shorter period of time, (c) decease and then eliminate the use of foreigners in production-only activities. For low capacity economies, foreign experts substitute for domestic skilled workers. But for higher capacity economies, foreign experts become complements to domestic skilled workers in that the former cease production-only activities and engage in production-training activities. But for very high-capacity economies, the LBS activity DS1 increasingly substitutes for foreign productiontraining at $\mathrm{t}=2$ (FS2) and the use of foreigners is confined to period $1 .^{8}$

Finally, Figure 9 shows welfare and X production in the three periods. Here we have a situation quite different from the cost results of the previous section. There we started with an uneven consumption pattern and achieved consumption smoothing as things improved. Here the low-capacity economies are stagnant and characterized by smooth (and low) consumption. Uneven consumption and growth occurs for high-capacity economies. ${ }^{9}$

\footnotetext{
${ }^{8}$ Activity FS1 continues to increase with even higher values of $a c$; it never goes to zero since it is vital to getting $\mathrm{X}$ output at $\mathrm{t}=1$ and $\mathrm{t}=2$, and for producing skilled workers for $\mathrm{t}=2$.

${ }^{9} \mathrm{X}_{1}$ is higher than $\mathrm{X}_{2}$ and $\mathrm{X}_{3}$ over the middle range because $\mathrm{X}_{1}$ is important for generating skilled workers for $t=2$. That is, activity FS1 is run at a high level because of the valuable joint outputs of $S_{2}$ and $\mathrm{S}_{3}$.
} 


\section{6. $\quad \underline{\text { Summary }}$}

We can now summarize the results of our three-period model.

(1) Importing foreign experts allows the economy to produce skilled workers earlier and at a lower cost than through learning from scratch: reinventing the wheel. This in turn allows earlier and large consumption of the good produced using skilled labor.

(2) As the cost of foreign experts falls from an initially prohibitive level, they are used sparingly for one period only, with the newly-skilled domestic workers training additional domestic workers in period 2. As foreign experts become cheaper, all training is done by foreigners, and when they are very cheap it does not pay to train anyone, and all production of $\mathrm{X}$ is done by the foreigners.

(3) As the cost of foreign experts falls from an initially prohibitive level, gains from trade are initially taken in the form of having skilled workers earlier rather than in having more skilled workers by $\mathrm{t}=3$, and in having $\mathrm{X}$ consumption earlier rather than (significantly) more $\mathrm{X}$ over three periods.

(4) Taken together, (2) and (3) imply that foreign experts and domestic skilled workers are complements up to the point where the former are very cheap. They are complements in the sense that a fall in the price of foreign experts induces the creation of domestic skilled workers earlier, and a large cumulative number of domestic skilled-worker years, although not necessarily a larger total of domestic skilled workers at $\mathrm{t}=3$. When foreigners are very cheap, foreign experts and domestic skilled workers are substitutes in the sense that further falls in the cost of experts reduces and eventually eliminates domestic training.

(5) Our second experiment involved changing the economy's learning or "absorptive" 
capacity: the efficiency with which unskilled workers are transformed into skilled workers in both LBS and LBW acitivities. Results show that economies with successively higher capacities (a) rely proportionately less on foreigner experts, (b) use foreign experts for a shorter period of time, (c) decease and then eliminate the use of foreigners in production-only activities.

(6) For low capacity economies, foreign experts substitute for domestic skilled workers. But for higher capacity economies, foreign experts become complements to domestic skilled workers in that the former cease production-only activities and engage in production-training activities. But for very high-capacity economies, the LBS activity DS1 increasingly substitutes for foreign production-training at $\mathrm{t}=2$ (FS2) and the use of foreigners is confined to period 1 .

(7) We also did an experiment constraining international borrowing to pay for experts in early years by imposing a period-by-period balance-of-trade constraint. Results here are generally intuitive in comparison to the case with borrowing permitted, so they are reported in an appendix for the cost experiment. Self-study persists at lower values of experts' costs than with borrowing. The use of foreign experts to train domestic workers is both reduced and spread out over time relative to the case with borrowing. There is less consumption smoothing, and consumption of $\mathrm{X}$ in period 1 in particular lags behind what is achieved in the case with borrowing.

(8) Borrowing supports more total domestic workers trained and more cumulative skilled-worker years than without, and in that sense we can say that access to foreign experts and to foreign borrowing are complements. 


\section{$\underline{\text { References }}$}

Blomstrom, Magnus, and Ari Kokko (1998), Foreign investment as a vehicle for international technology transfer, in: G.B. Navaretti, P. Dasgupta, K.-G. Maeler, and D. Siniscalco, eds., Creation and Transfer of Knolwedge , Springer-Verlag, Berlin, 279-311.

Blomström, Magnus and Fredrik Sjöholm (1999), “Technology transfer and spillovers: does local participation with multinationals matter?”, European Economic Review 43, 915923.

Ethier, Wilfred J. and James R. Markusen (1996), Multinational firms, technology diffusion and trade, Journal of International Economics 41, 1-28.

Fosfuri, Andrea, Massimo Motta and Thomas Rønde (2001), Foreign direct investments and spillovers through workers' mobility, Journal of International Economics 53, 205-222.

Glass, Amy J. and Kamal Saggi (2002), “Multinational firms and technology transfer”, Scandinavian Journal of Economics 104, 495-5134.

Gong, G. And Wolfgang Keller (2003), “Convergence and polarization in global income levels: a review of recent results on the role of international technology diffusion”, Research Policy 32, 1055-1079.

Hall, Gronwyn H., and Beethika Khan (2003), “Adoption of New Technology”, NBER working paper 9730, May.

Hobday, Michael (1995), Innovation in east asia: the challenge to japan, Aldershot, London.

Katz, J.M. (1987), Technology creation in latin american manufacturing industries, St. Martin's Press, New York.

Keller, Wolfgang (1998), “Are international R\&D spillovers trade-related? Analyzing spillovers among randomly matched trade partners”, European Economic Review 42, 1469-1481.

Keller, Wolfgang (2002), “Geographic localization of international technology diffusion”, American Economic Review 92, 120-142.

Keller, Wolfgang (2000), “Do trade patterns and technology flows affect productivity growth?”, World Bank Economic Review 14, 17-47.

Markusen, James R. (2001), “Contracts, Intellectual Property Rights, and Multinational Investment in Developing Countries”, Journal of International Economics 53, 189-204. 
Markusen, James R. Anthony J. Venables (1999), "Foreign Direct Investment as a Catalyst for Industrial Development", European Economic Review 43, 335-356.

Markusen, James R., Thomas F. Rutherford and David Tarr (2004), “Trade and Foreign Direct Investment in Producer Services and the Market for Domestic Expertise”, NBER working paper 7700, Under revision for the Canadian Journal of Economics.

Smarzynska, Beata (2004), "Does foreign direct investment increase the productivity of domestic firms? In search of spillovers through backward linkages”, American Economic Review forthcoming.

Smarzynska, Beata and Mariana Spatareanu (2003), “To share or not to share: does local participation matter for spillovers from foreign direct investment?”, World Bank working paper 3118. 
Appendix: No international borrowing

The assumption in the model that foreign borrowing is allowed to pay for foreign experts in early years may not be realistic for many developing economies. Thus in this section we briefly consider the extreme opposite assumption that there is no international borrowing allowed. Obviously, this makes no difference in autarky. In addition, we have calibrated the model so that at a price for foreign experts of one (right-hand end of our figures), there is perfect consumption smoothing and so again the ability to borrow or not makes no difference. The ability to borrow thus matters between autarky and the price of one.

The model is now modified to have three foreign-exchange "goods" instead of one. Experts can only be imported in period 1 in exchange for $\mathrm{Y}_{1}$ and similarly for experts in periods 2 and 3. Thus trade balances within each period.

Figure A1 shows the regimes in the same manner as Figure 1 and Figure 5 for decreasing costs of consultants top to bottom. Results are rather intuitive, and so let us just list them in comparison to the case of Figure 1 with borrowing allowed.

(1) The self-study/training activity DS1 continues to be active at lower experts' cost than with borrowing.

(2) The activity DS2, in which domestic skilled workers trained by foreign experts in period 1 train more domestic workers in period 2 continues to be active at lower experts' cost than with borrowing.

(3) Activity FS2, in which foreign experts are employed to train a second-generation of domestic workers in period 2 is now active for an intermediate range of costs. This activity is never active with borrowing allowed.

(4) The use of foreign experts to simply produce and not train (FN1, FN2, FN3) now occurs at higher costs than with borrowing allowed.

Thus the international borrowing constraint implies that self-study/training persists at lower experts' costs, but conversely experts are use to produce without training any domestic workers at higher experts' costs. Somewhat loosely, we could say that the use of foreign experts for training is both reduced and is shifted later in time (or spread out over time).

Figure A2 shows the equivalent of Figure 2, and differs from the latter by the fact that the activity FS2 (foreigners training more domestics at $t=2$ ) is now used at intermediate experts' cost. Figure A2 shows that there is more reliance on self-study (DS1) and training by domestic skilled workers (DS2) at moderate costs and, when all training is done by experts when costs are low, fewer domestic workers are trained. For all levels of experts' cost except the two endpoints, fewer domestic workers are trained and the total cumulative skilled-worker years is less when borrowing is not allowed (results not shown).

Lastly, Figure A3 reveals again that the welfare benefits of access to foreign experts are taken in the form of earlier $\mathrm{X}$ consumption up to the point where experts' cost are moderate. There is less consumption smoothing, and complete smoothing is not achieved until the price of experts falls to one. Between autarky and a price of one, welfare is somewhat lower (but not dramatically so) with borrowing constrained. 
Figure 1: Production and training regimes - cost of foreign experts

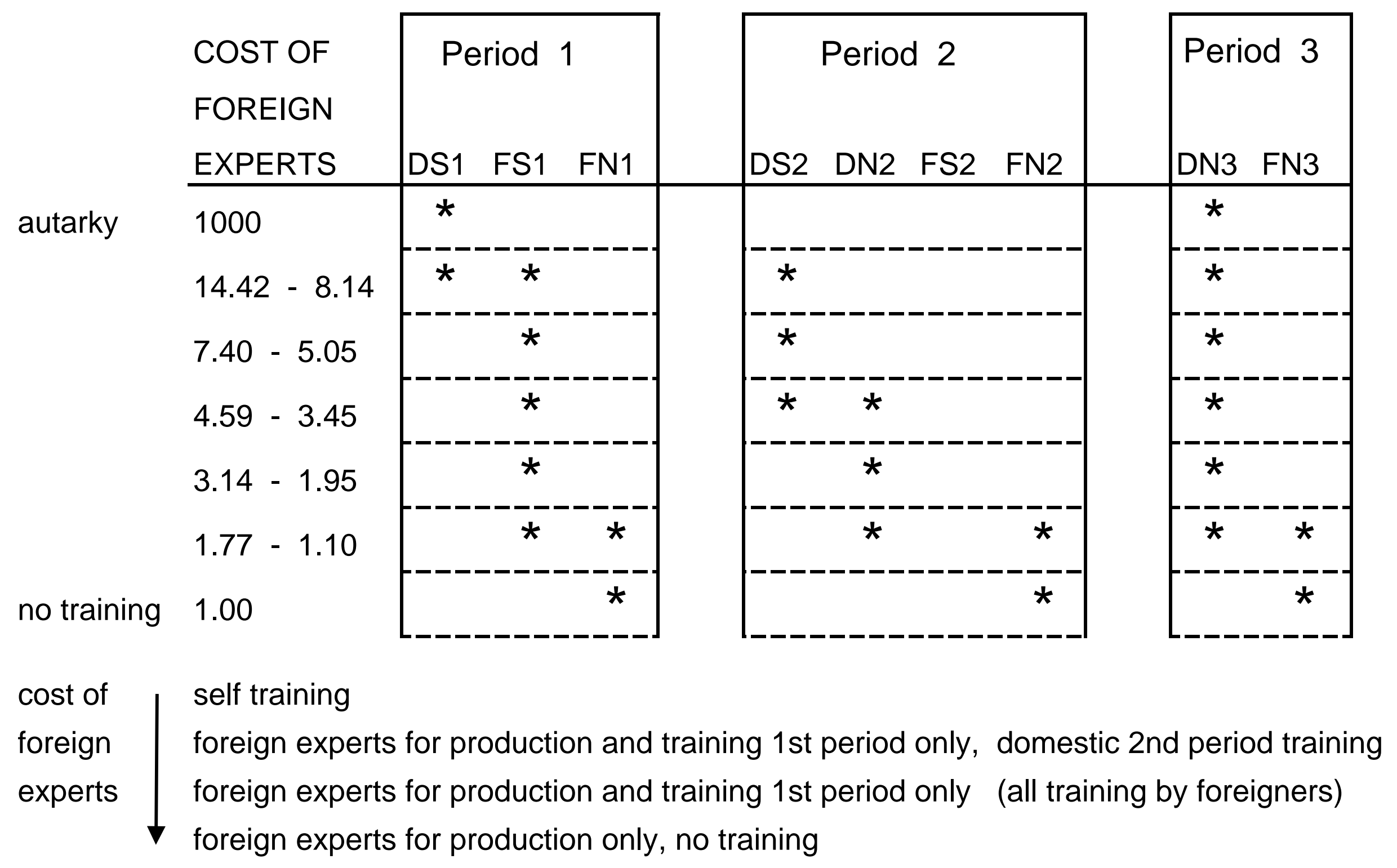


Figures 2: Total self/domestic trained and trained by foreign experts by $\mathrm{t}=3$

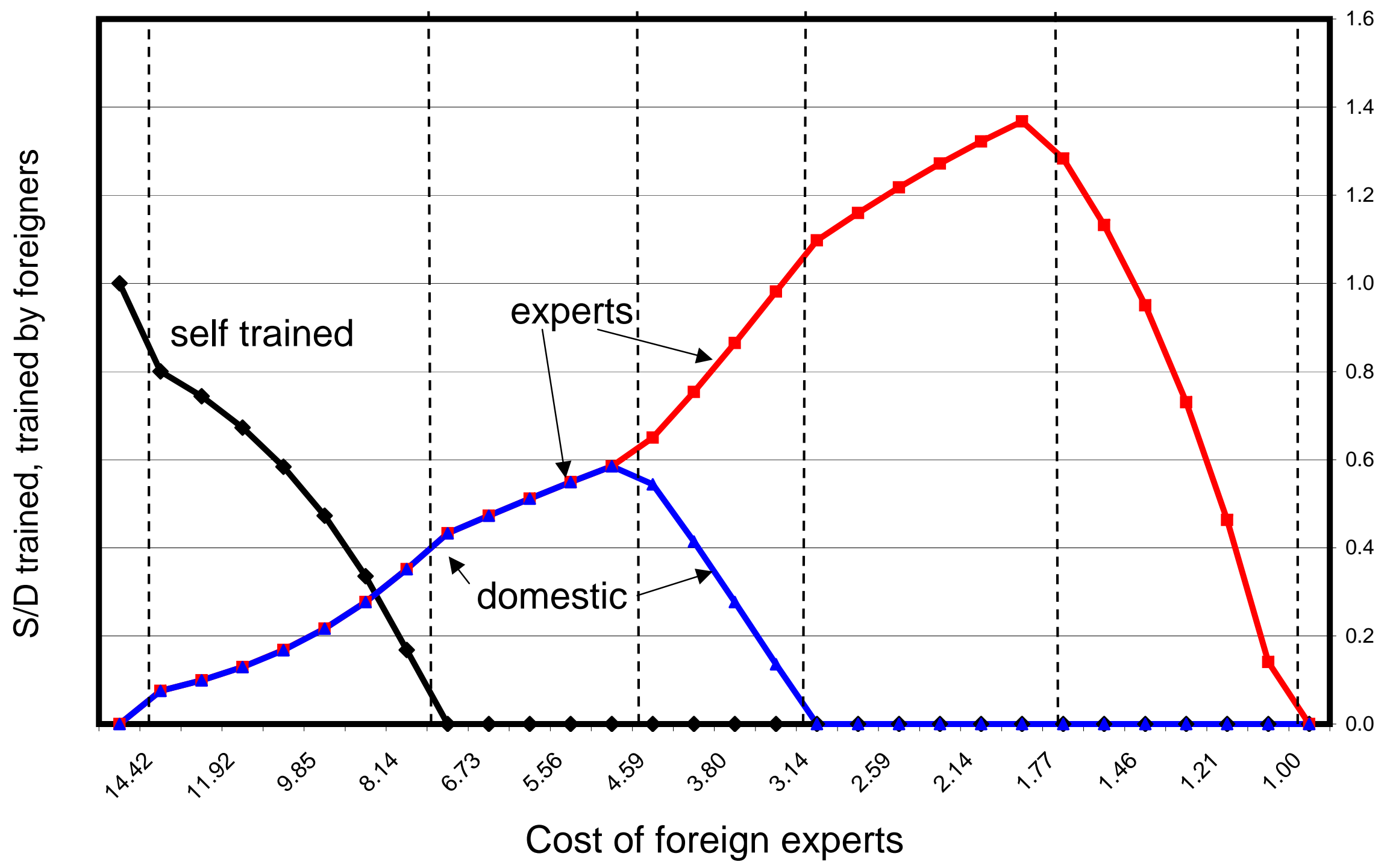

$\rightarrow$ Self trained (DT1) $\rightarrow$ Trained by for (FS1 + FS2) $\rightarrow$ Domestic trained (DS2) 
Figures 3: Total trained, total skilled-worker years

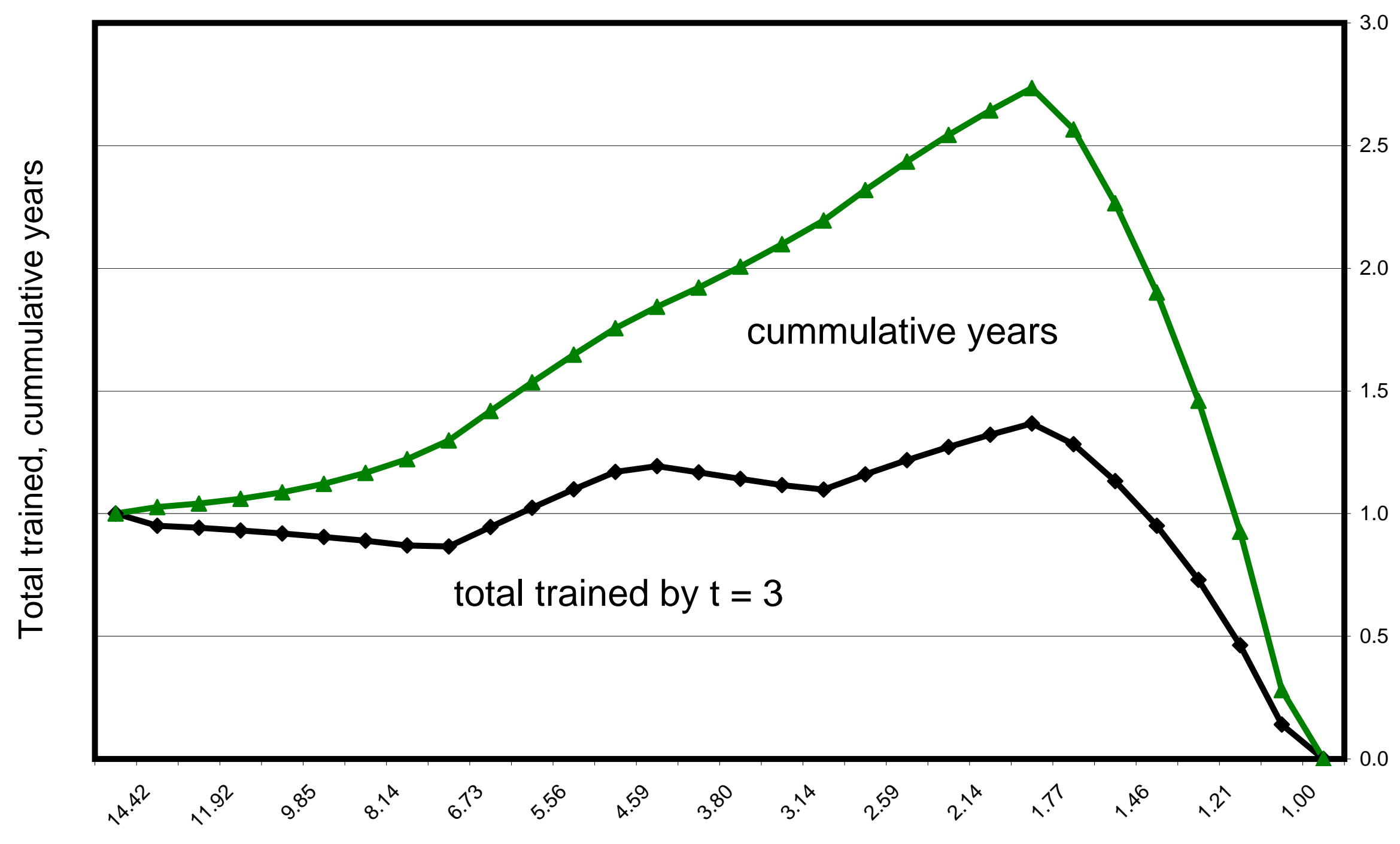

Cost of foreign experts

$\rightarrow$ Total trained by $\mathrm{t}=3 \rightarrow$ Cummulative domestic skilled worker years 
Figure 4: $\mathrm{X}$ production by period, welfare

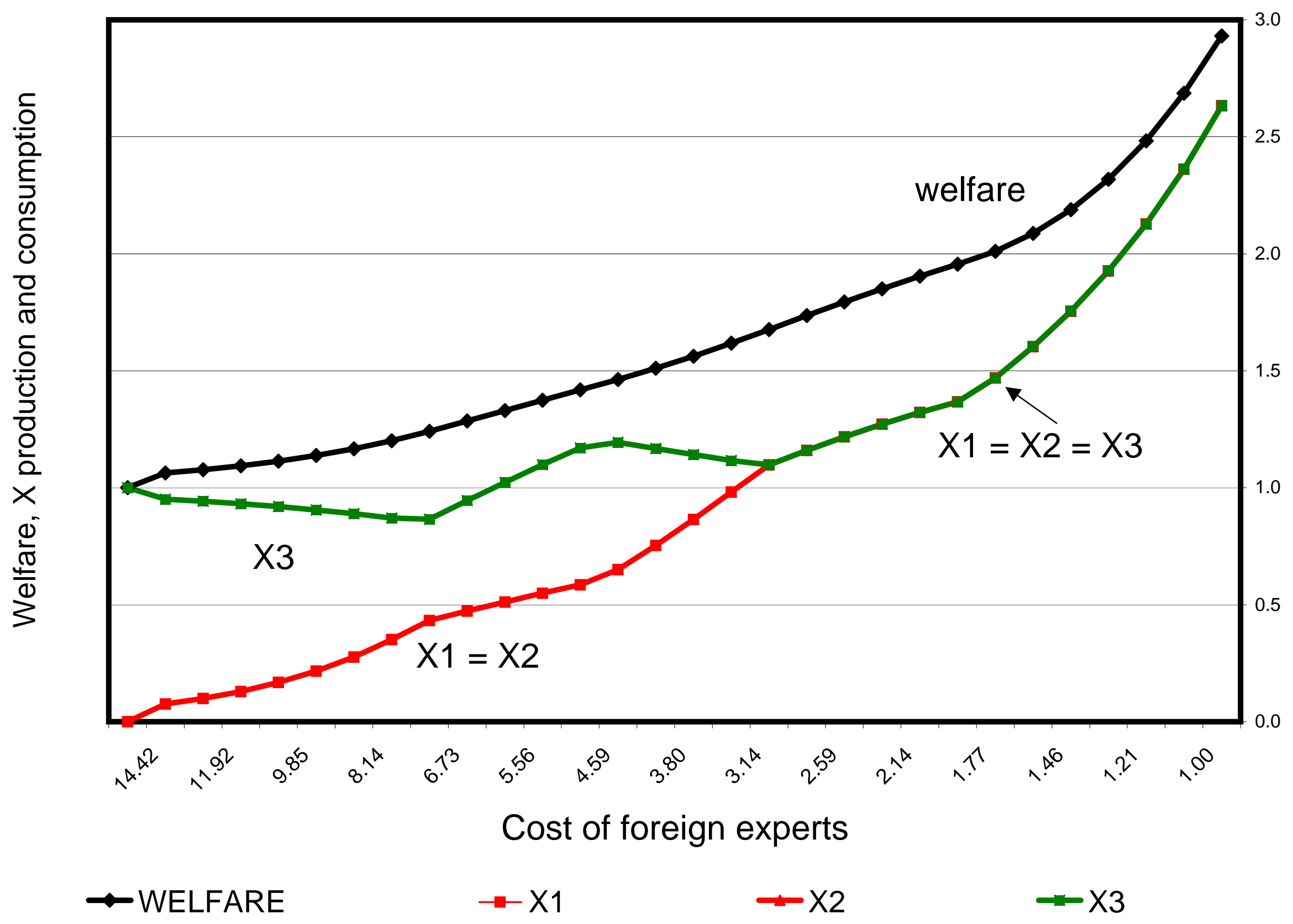


Figure 5: Production and training regimes - learning capacity

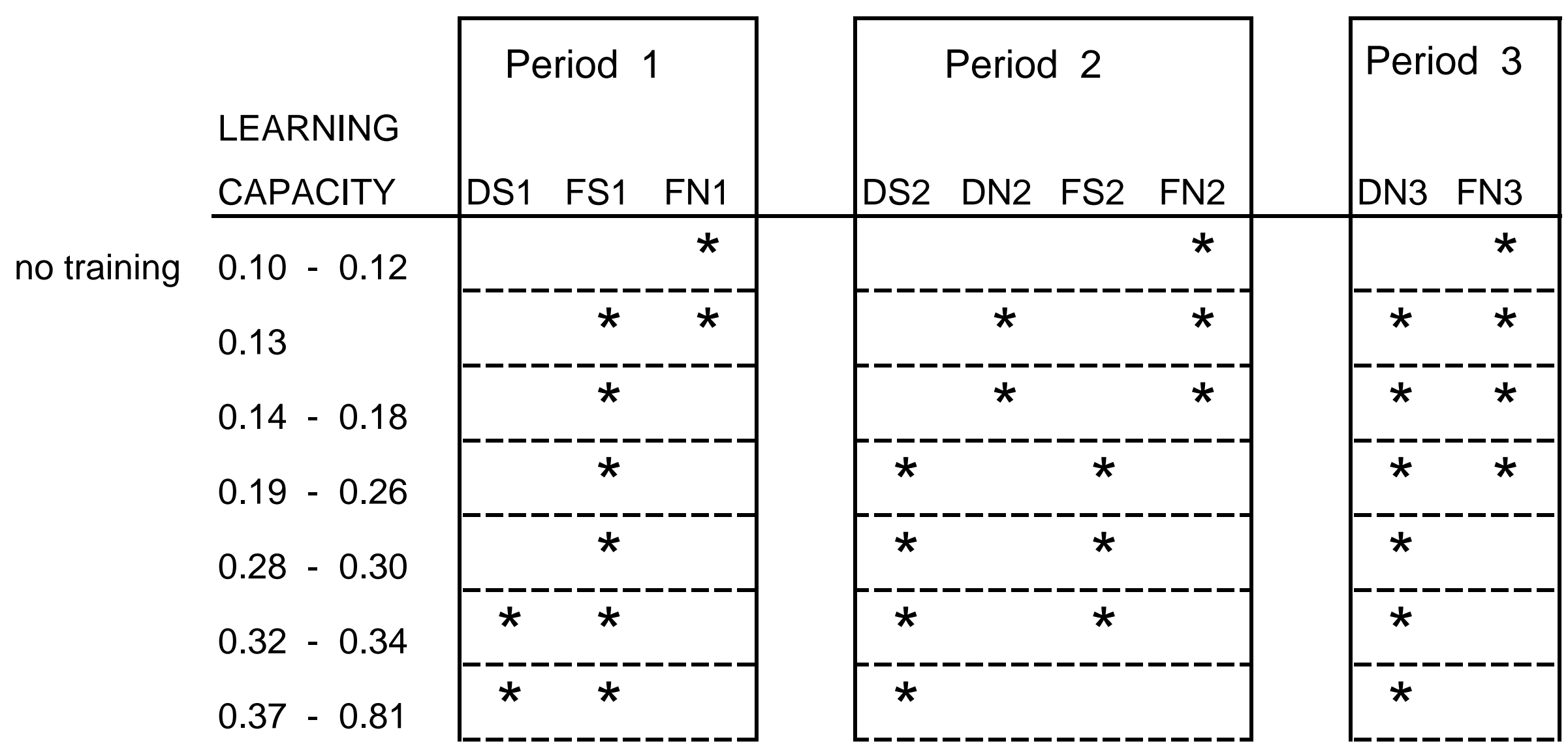

cost of

foreign experts for production only, no training

foreign foreign experts for production and training 1st period, production only $t=2,3$

experts foreign experts for production and training 1st and 2nd period, domestic training $\mathrm{t}=2$ foreign experts for production and training 1st period, self learning, domestic training $t=2$ 
Figure 6: Total self/domestic trained and trained by foreign experts by $\mathrm{t}=3$

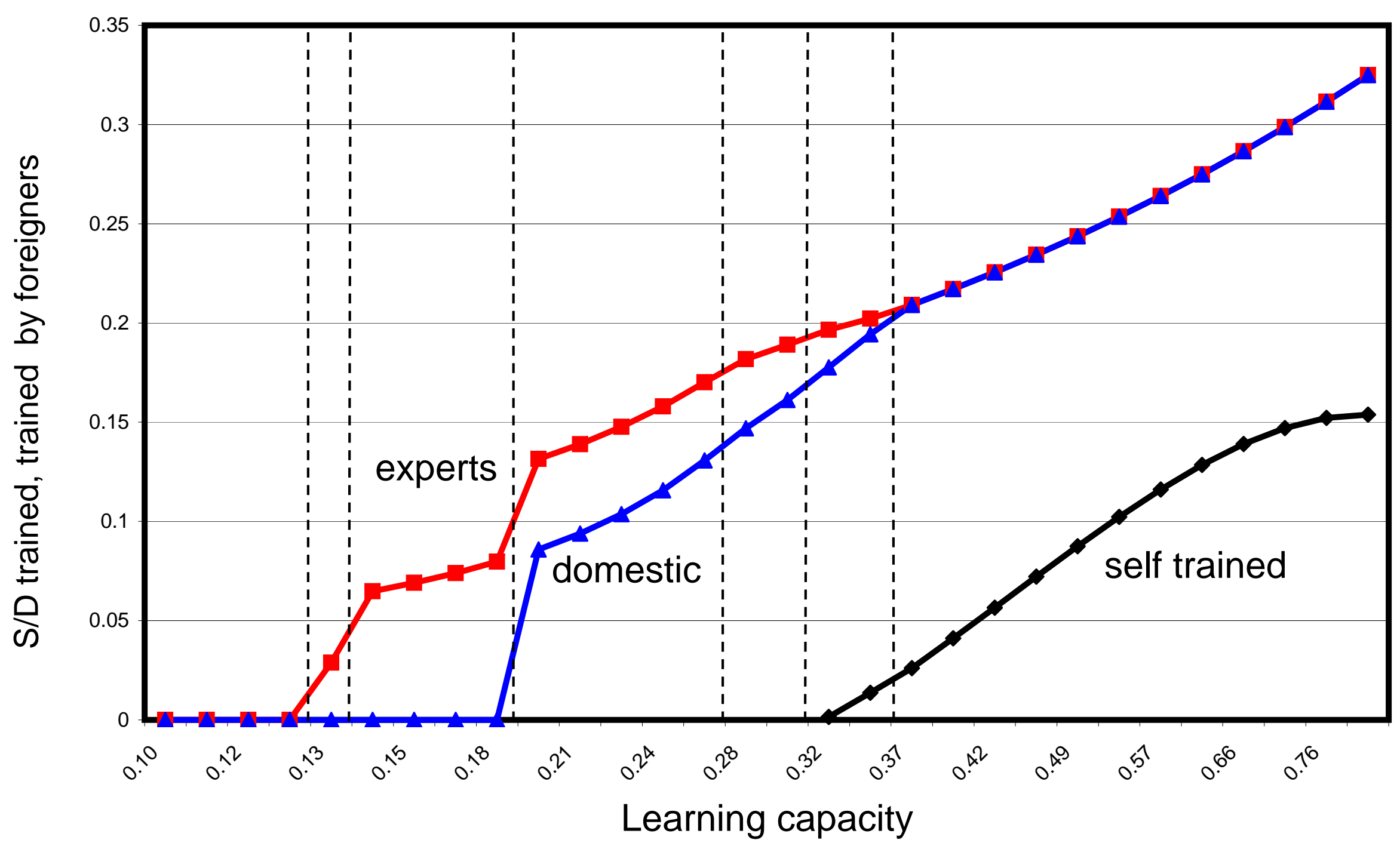

$\rightarrow$ Self trained (DS1) $\rightarrow$ Trained by for (FS1+FS2) $\rightarrow$ Domestic trained (DS2) 
Figure 7: Use of foreign experts by period

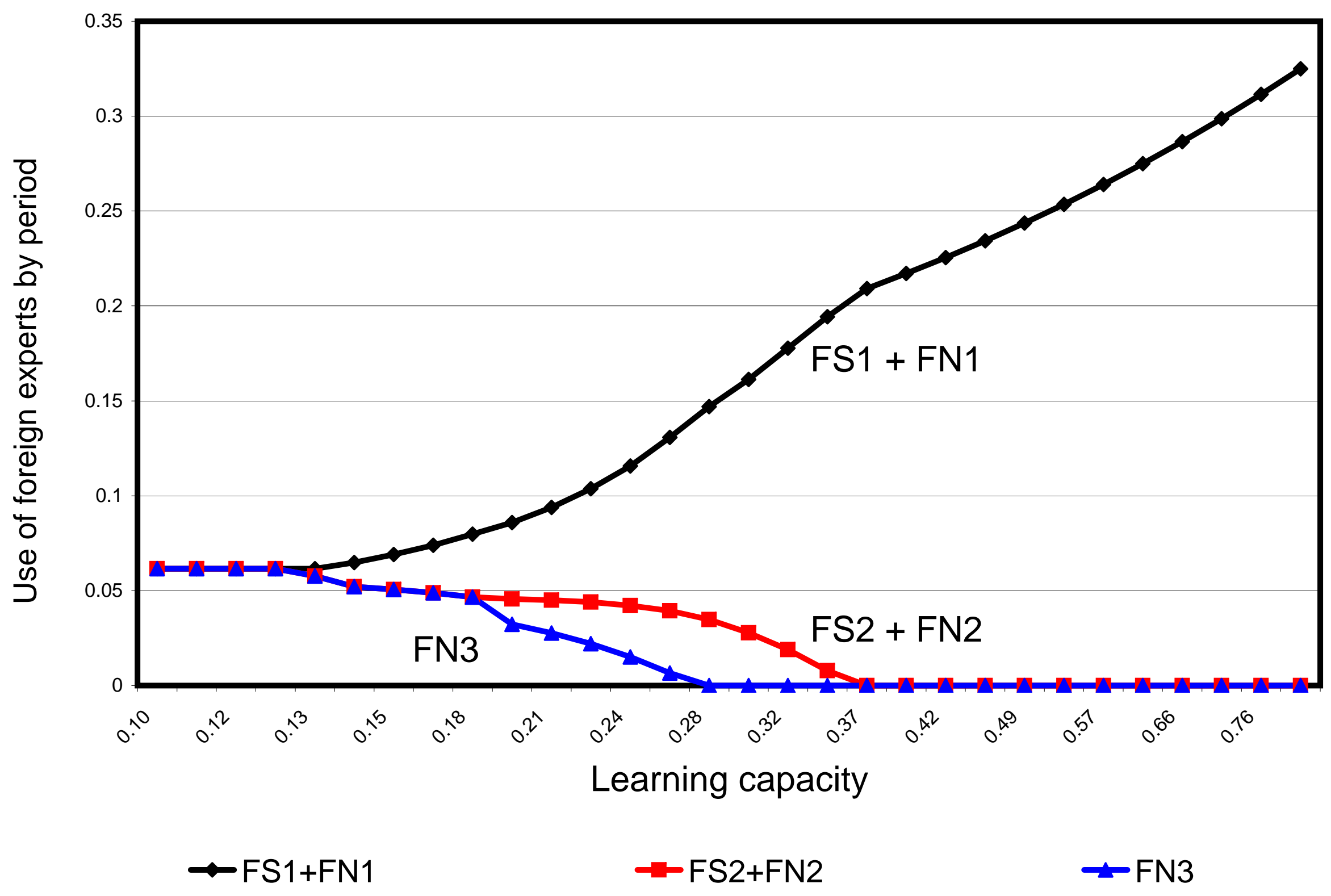


Figure 8: Use of foreign experts for training versus production only over three periods

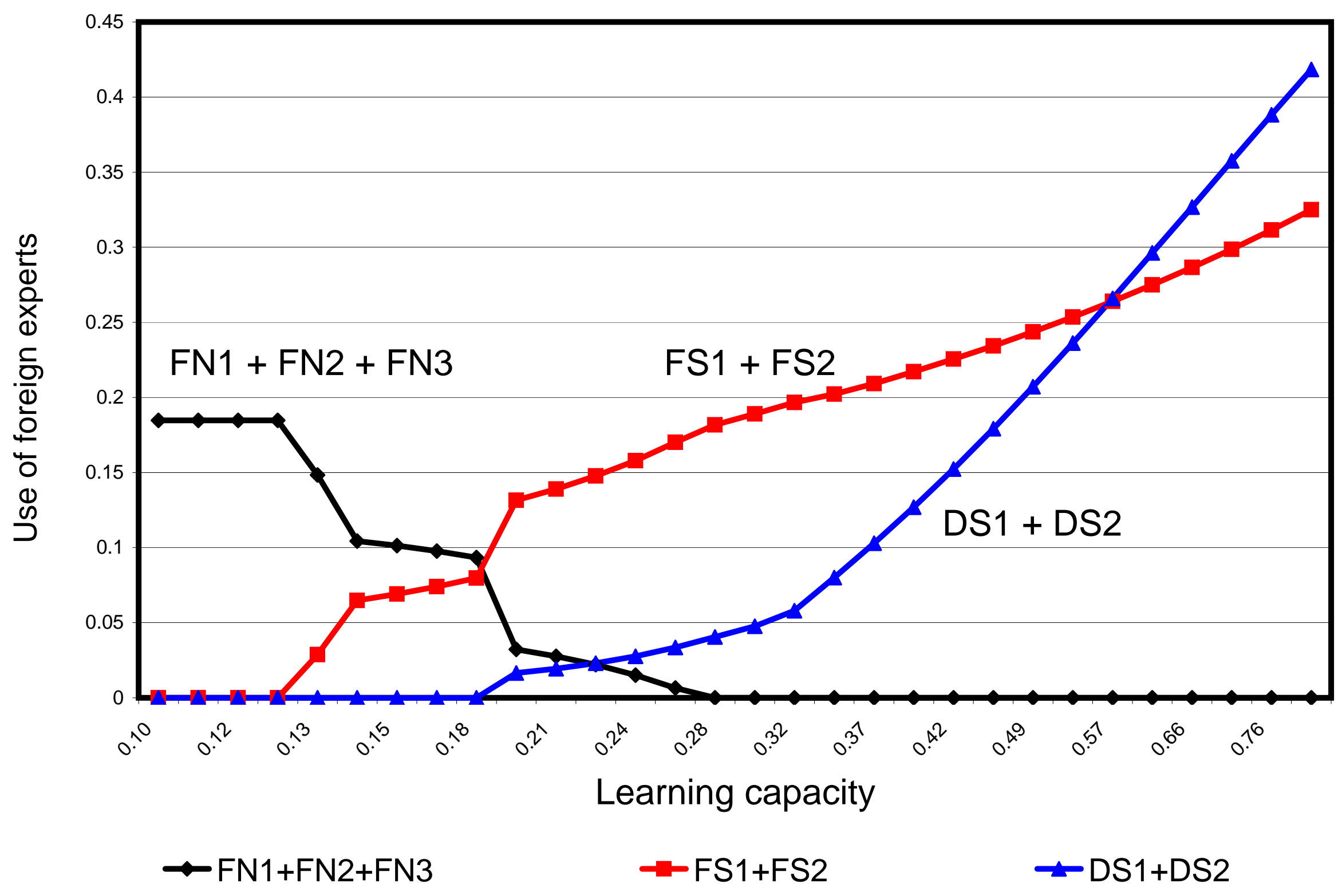


Figure 9: $X$ production by period, welfare

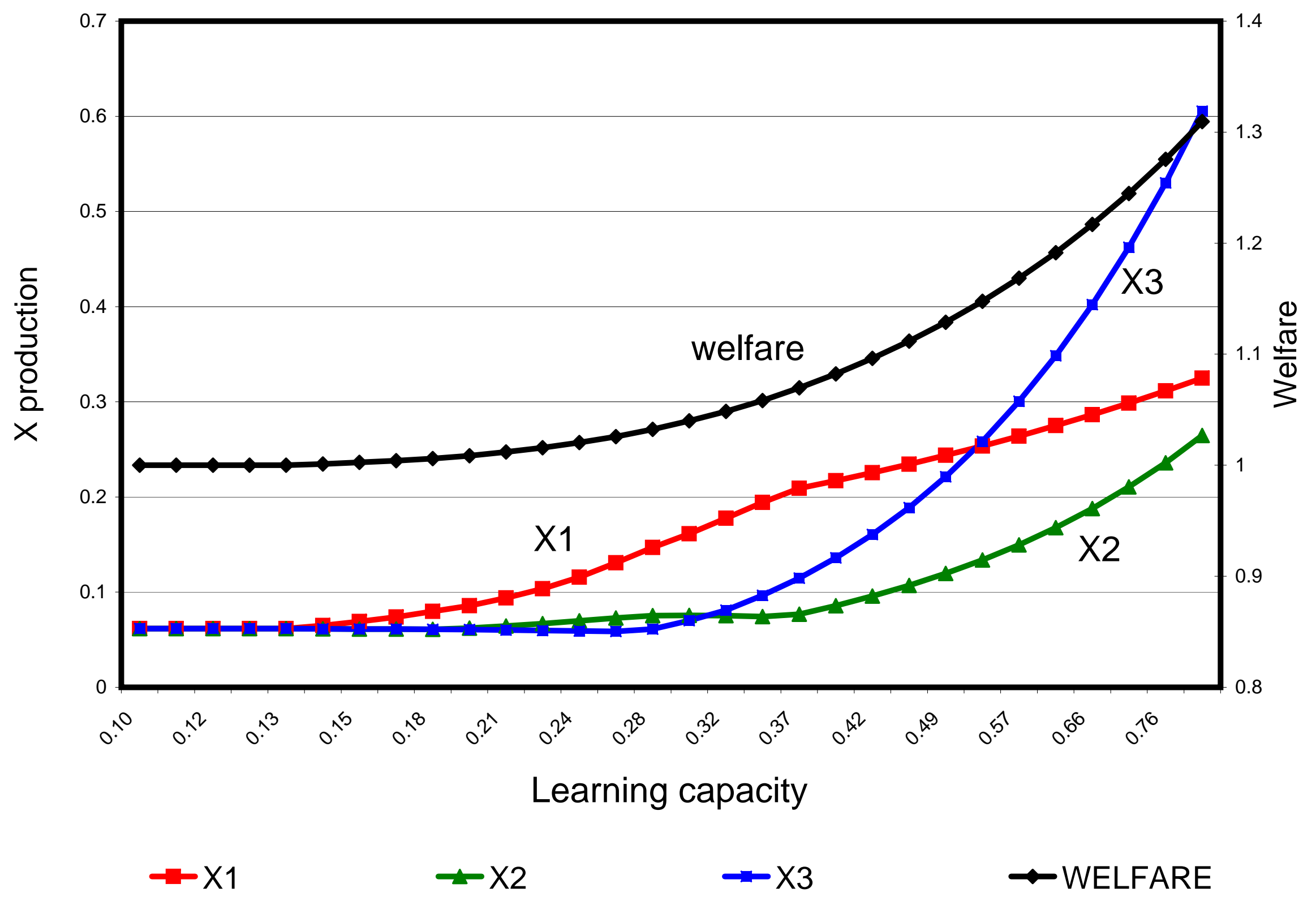


Figure A1: Production and training regimes with no international borrowing allowed - cost of foreign experts

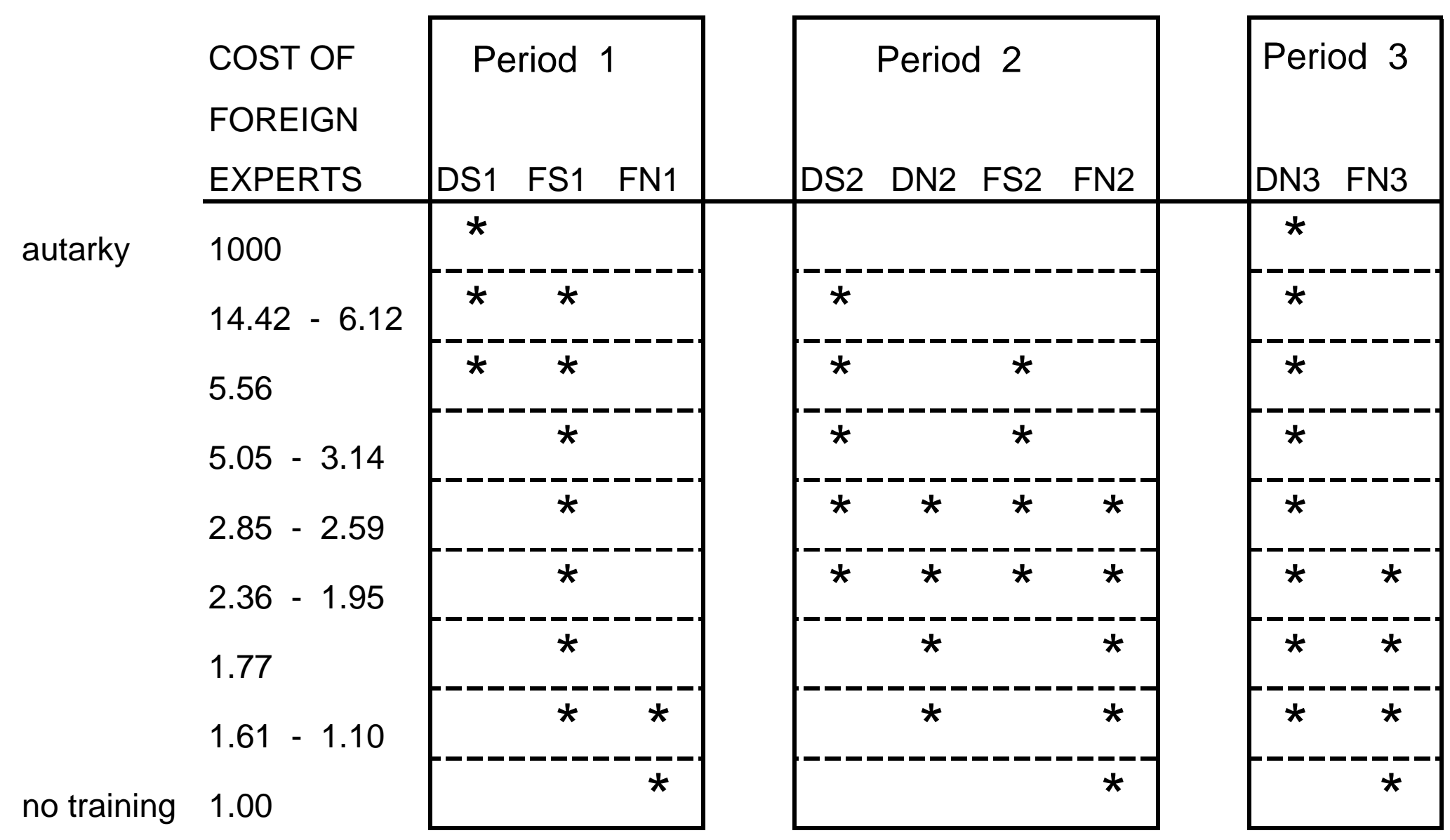

cost of foreign self training

experts foreign experts for production and training 1st period only, domestic 2nd period training foreign experts for production and training 1st-2nd period, domestic 2nd period training foreign experts for production and training 1st period only (all training by foreigners) foreign experts for production only, no training 
Figures A2: Total self/domestic trained and trained by foreign experts by $\mathrm{t}=3$ (no international borrowing)

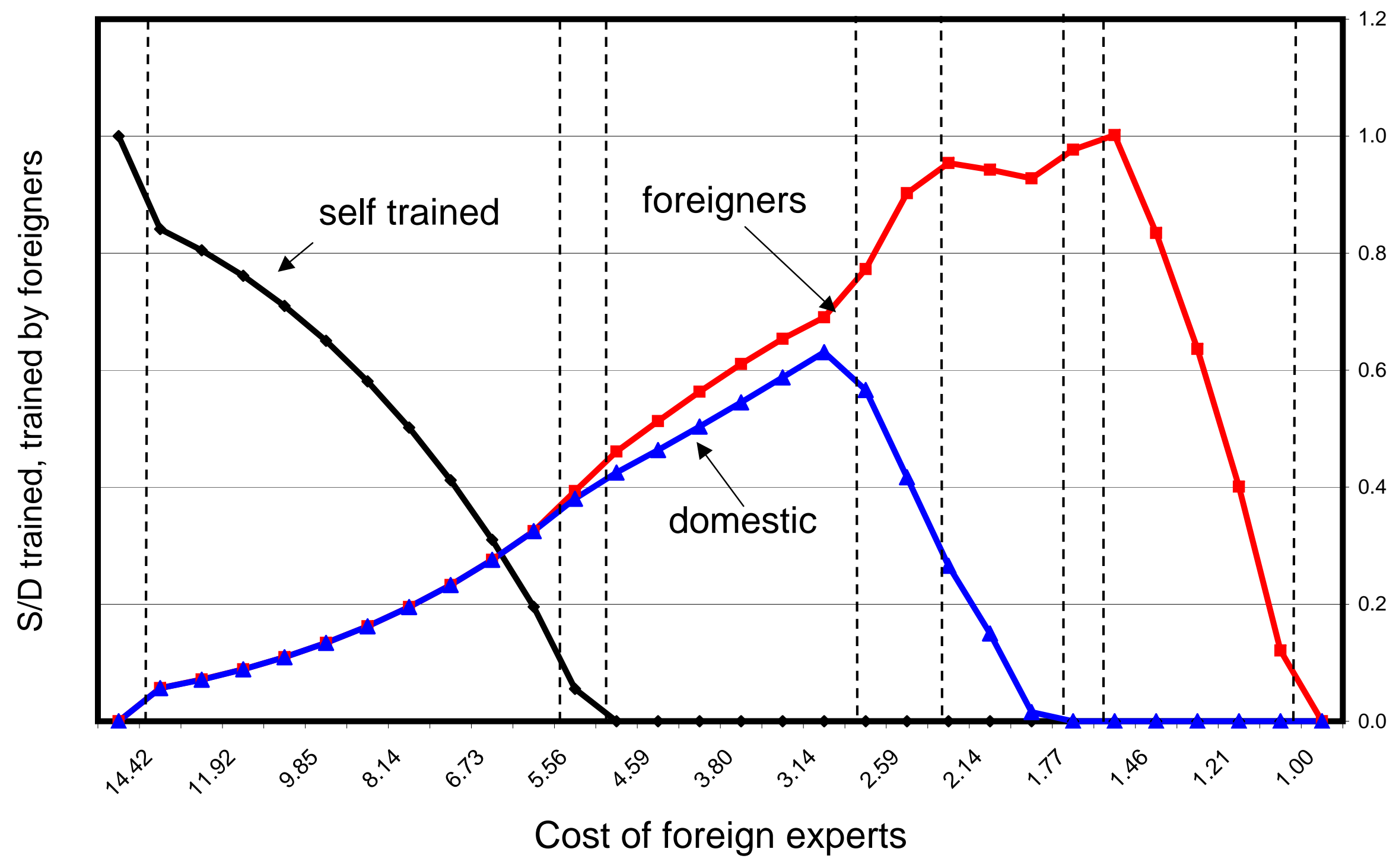


Figures A3: Welfare, $\mathrm{X}$ consumption (no international borrowing)

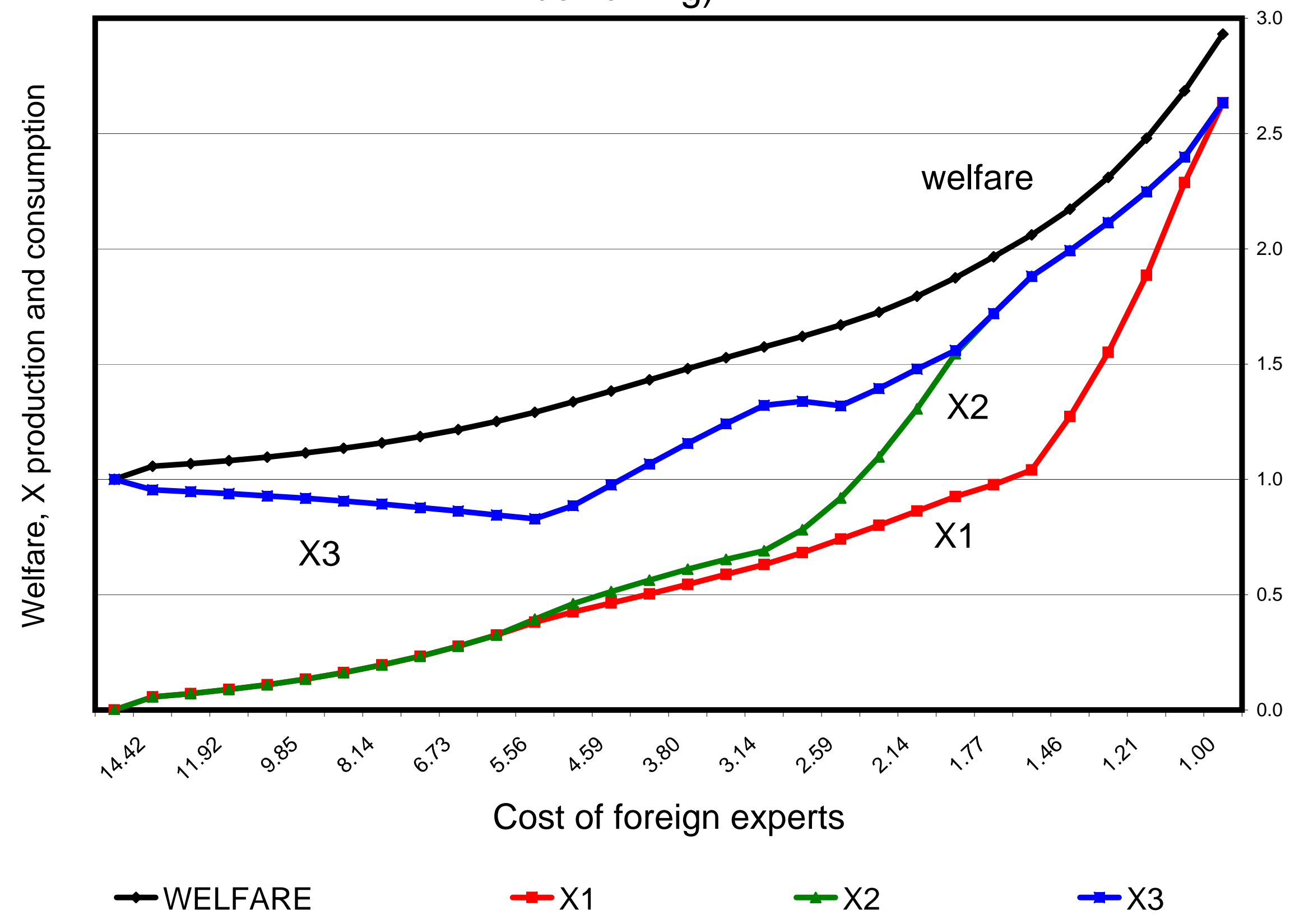

